\title{
Modelling Multi-layer Hydronic Radiators
}

\author{
Liguo Chen*, Bjørn Reidar Sørensen \\ UiT The Arctic University of Norway, Department of Building, Energy and Material Technology, PO Box 385, 8514 Narvik, Norway
}

\begin{abstract}
This report simulates Purmo type C22 and C33 radiators with both standard calculation and heat transfer method with help of Matlab/Simulink. Simulation results are presented to describe the radiators' thermal performances with different simulation strategies. The deviations between two different calculation methods are identified and the heat transfer radiator model can be improved with more investigations regarding thermal dynamics and controlling strategy. Under simulation scenarios of simple room model with a PID controller, type C33 has shorter response time and faster stabilization of room temperature; and it has lower outflow temperature, which implies higher energy efficiency.
\end{abstract}

\section{Introduction}

During the last decades, existing buildings are increasingly being renovated in order to reduce energy consumption as well as to improve living standards for the inhabitants. There has been emerging technologies and noticeable changes in buildings and heating systems. New and renovated buildings become less energy demanding for space heating due to higher insulation values and better air tightness; and utilization of renewable energy is an increasingly common option, which leads to higher demand for energy flexibility. The low temperature hydronic heating system is one of the promising energyefficient alternatives, since this heating solution is compatible with varying energy sources such as heat pumps and solar energy, furthermore it can contribute to improved indoor air quality and thermal comfort.

Within this context, the low temperature hydronic system has gained research attention lately. Besides large surface heat emitters such as floor heating, radiators are still compatible with the low temperature operation with improved designs. There are some investigations on low temperature hydronic radiators. For instance, Maivel and Kurnitski [1] studied distribution and emission losses of low temperature radiator heating by simulating the system with several dynamic components. The radiator model included details regarding configuration and thermal mass of the radiator, together with thermal behaviors with consideration of front and rear panel surface. Prek and Krese [2] provided an improved heat output regulation concept for multi-panel radiators with experimental validation. The radiator was tested under both nominal steady state and transient conditions. Pedersen et al. [3] developed a dynamic hydronic radiator model and investigated its performance under three model predictive control schemes.

The aforementioned researches provided great examples for modeling hydronic radiators, but they did not take into account multi-layer radiators, which are the prevalent heat emitter in practice. The objective of this paper is to construct a multilayer radiator model to simulate and evaluate its performance under low temperature operation. Several case scenarios were created to investigate hydronic radiator's thermal performance with multi-layer designs.

\section{Method}

\subsection{Numerical model of multi-layer radiator}

The heat stored in a substance can be express as equation (1):

$$
Q=c \cdot m \cdot \Delta \mathrm{T}
$$

Where $\mathrm{Q}$ is heat output, $\mathrm{c}$ is specific heat capacity, $\mathrm{m}$ is mass and $\Delta \mathrm{T}$ is the temperature difference. Equation (2) describes the heat balance in a hydronic radiator. The delivered heat is partly stored in metal material of radiator and water mass that contained inside the radiator's water channels, and the emitted heat is the heat output of the radiator.

$$
\dot{Q}=\dot{Q}_{\text {water }}+\dot{Q}_{\text {metal }}+\dot{Q}_{\text {emitted }}
$$

Producers provide a standard approach to determine the heat performance of radiators, see equation (3) and (4):

$$
\begin{gathered}
\dot{m}_{w} \cdot c_{w} \cdot \frac{d T}{d t}= \\
\left(m_{w} \cdot c_{w}+m_{\text {metal }} \cdot c_{\text {metal }}\right) \cdot T_{\text {out }}+Q_{N} \cdot\left(\frac{\Delta T}{\Delta T_{N}}\right)^{n} \\
\Delta T=\frac{T_{\text {in }}-T_{\text {out }}}{\ln \frac{T_{\text {in }}-T_{\text {air }}}{T_{\text {out }}-T_{\text {air }}}}
\end{gathered}
$$

Where $Q_{N}$ is nominal heat output and $\Delta T_{N}$ is the logarithmic temperature difference at nominal condition, with consideration of heat capacitances. On the other hand, when the flow rate is high enough and $T_{\text {in }} \approx T_{\text {out }}$

\footnotetext{
${ }^{*}$ Corresponding author: liguo.chen@uit.no

Author: bjorn.r.sorensen@uit.no
} 
Table 1. Radiator specifications

\begin{tabular}{|c|c|c|c|c|c|}
\hline Geometry & $\mathbf{C 2 2}$ & $\mathbf{C 3 3}$ & Nominal condition & $\mathbf{C 2 2}$ & $\mathbf{C 3 3}$ \\
\hline Height & $500 \mathrm{~mm}$ & $500 \mathrm{~mm}$ & Tin/Tout/Tair & $55 / 45 / 20^{\circ} \mathrm{C}$ & $55 / 45 / 20^{\circ} \mathrm{C}$ \\
\hline Length & $1000 \mathrm{~mm}$ & $1000 \mathrm{~mm}$ & Heat output & $740 \mathrm{~W}$ & $1020 \mathrm{~W}$ \\
\hline Depth & $102 \mathrm{~mm}$ & $152 \mathrm{~mm}$ & Working pressure & $10 \mathrm{bar}$ & $10 \mathrm{bar}$ \\
\hline Metal weight & $27.7 \mathrm{~kg}$ & $41.6 \mathrm{~kg}$ & Radiator exponent $\mathrm{n}$ & 1.3270 & 1.3371 \\
\hline Heat capacity c metal & $0.51 \mathrm{~kJ} \mathrm{~kg}^{-1} \mathrm{~K}^{-1}$ & $0.51 \mathrm{~kJ} \mathrm{~kg}^{-1} \mathrm{~K}^{-1}$ & Nominal mass flow rate & $0.0176 \mathrm{~kg} / \mathrm{s}$ & $0.0244 \mathrm{~kg} / \mathrm{s}$ \\
\hline Heat capacity c water & $4.19 \mathrm{~kJ} \mathrm{~kg}^{-1} \mathrm{~K}^{-1}$ & $4.19 \mathrm{~kJ} \mathrm{~kg}^{-1} \mathrm{~K}^{-1}$ & $\Delta T_{N}$ & 29.72 & 29.72 \\
\hline Water mass & $5.48 \mathrm{~kg}$ & $8.17 \mathrm{~kg}$ & & & \\
\hline
\end{tabular}

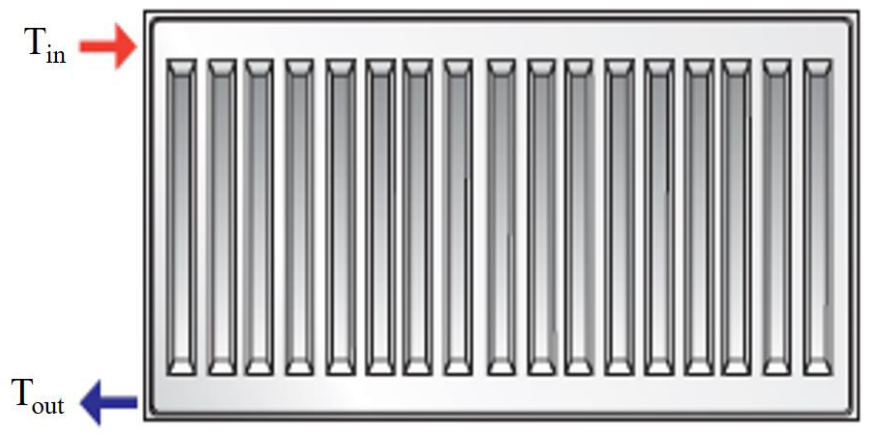

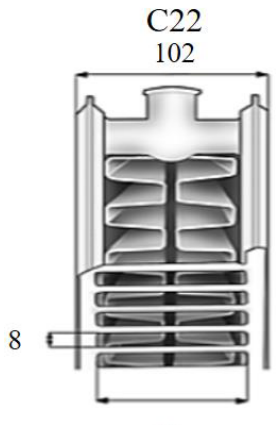

78

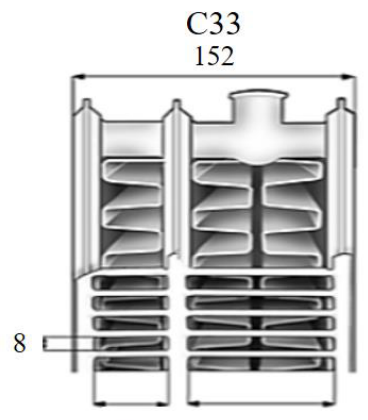

78

Fig. 1. Purmo $\mathrm{C} 22$ and $\mathrm{C} 33$ radiator: connection scheme and top views

$\Delta T$ cannot be solved with equation (4). Hence it is can be simplified as following equation:

$$
\Delta T_{m}=0.5 \cdot\left(T_{\text {in }}-T_{\text {out }}\right)-T_{\text {air }}
$$

The selected radiators are common market types, Purmo type 22 and 33 compact panel radiator (refers as $\mathrm{C} 22$ and $\mathrm{C} 33$ respectively in following content), and the relevant configurations are listed in Table 1.

Fig. 1 presents the connection scheme and top views of the selected radiators. The supply and return water pipes are connected on the same side. C22 has double panels while $\mathrm{C} 33$ has triple. Both radiators have convection fins between panels.

The standard calculation approach according to nominal values does not provide details about how the heat is emitted regarding radiator's actual geometry. Hence a heat transfer model is built as illustrated in Fig.2. The heat transfer happens on the room facing radiator surfaces; it includes both long wave radiation and convection. While for the fins, only convection is considered; radiation by fins is neglected but the air temperature between panels is considered higher than room temperature.

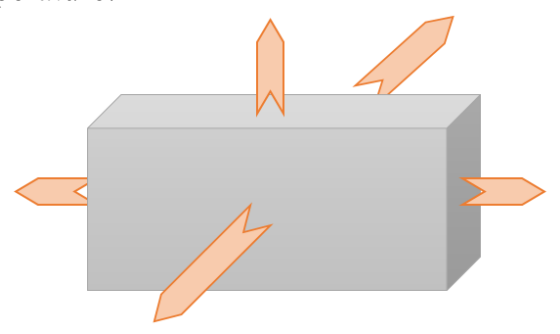

Fig. 2. Heat transfer model

The heat output is estimated according to the heat transfer governing equations for convection and radiation:

$$
\dot{Q}_{\text {emitted }}=\sum \dot{Q}_{\text {convection }}+\sum \dot{Q}_{\text {radiation }}
$$

$$
\begin{gathered}
\dot{Q}_{\text {convection }}=h \cdot A \cdot\left(T_{\text {surface }}-T_{\text {air }}\right) \\
\dot{Q}_{\text {radiation }}=\varepsilon \cdot \sigma \cdot A \cdot\left(T_{\text {surface }}^{4}-T_{\text {wall }}^{4}\right)
\end{gathered}
$$

As the heat transfer with convection and radiation are both complex mechanism, certain parameters and conditions are simplified in order to present a model with engineering significance. The interactions between walls and radiator surface, i.e. reflections and absorptions, are not considered. The convective heat transfer coefficient $h$ is determined with following steps:

$$
\begin{gathered}
R a=\frac{\beta \cdot g \cdot\left(T_{\text {surface }}-T_{\text {air }}\right) \cdot L^{3}}{v^{2}} \cdot \operatorname{Pr} \\
N u=\left\{0.825+\frac{0.387 R a^{1 / 6}}{\left[1+(0.492 / P r)^{9 / 16}\right]^{8 / 27}}\right\}^{2} \\
h_{S}=N u \cdot k / L \\
h_{C}=N u_{C} \cdot k / D_{h}
\end{gathered}
$$

Where $R a$ is local Rayleigh number, $g$ is the gravitational acceleration, $\beta$ is thermal expansion coefficient, $v$ is kinematic viscosity, $\operatorname{Pr}$ is the Prandtl number, $N u$ is Nusselt number. Equation (10) is applicable when $10^{-1} \leq R a \leq 10^{12}[4,5]$. The convective heat transfer coefficients $h_{S}$ and $h_{C}$ describe convections at the radiator surfaces and through fins respectively. More specifically, equation (11) describes free convection with vertical surface, while equation (12) present convention for fully developed laminar flow in channels. The top view of simplified fin structure with combination of vertical rectangular channels are illustrated in Fig.3; with 1 meter radiator length, the array of convection fins consist of 33 units of these fin structures. $h_{C}$ refers to the convective heat transfer coefficient in the rectangular channels which is estimated according to the principle of 
flow in noncircular tubes with consideration of hydraulic diameter $D_{h}[5]$. The estimated convective heat transfer coefficients are summarized in Table 2.

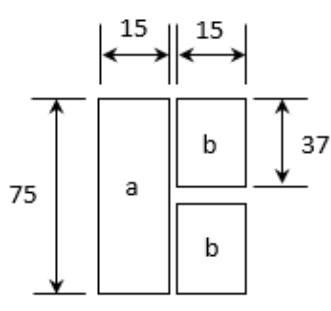

Simplified C22 fin structure

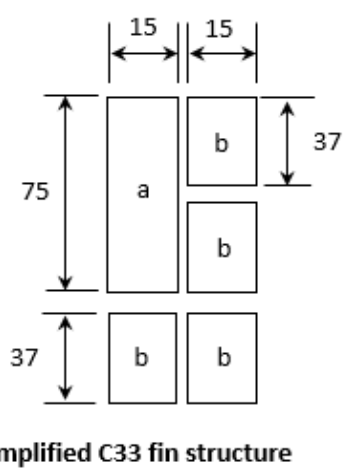

Simplified C33 fin structure
Fig. 3. The simplified fin structures for convective heat transfer estimation

Table 2. Convective heat transfer coefficients

\begin{tabular}{|c|c|c|c|c|}
\hline \multirow{2}{*}{} & \multirow{2}{*}{ Front panel } & \multirow{2}{*}{ Rear panel } & \multicolumn{2}{|c|}{ Fin } \\
\cline { 4 - 5 } & & & $\mathrm{a}$ & $\mathrm{b}$ \\
\hline$h$ & 4.84 & 4.84 & 4.46 & 4.12 \\
\hline
\end{tabular}

The model based on nominal conditions (standard method) serves as baseline model and the heat transfer model will be validated and compared against it. Certain simplifications and assumptions are listed below:

- $\quad$ The supply water temperature is constant at $55^{\circ} \mathrm{C}$.

- The system is hydraulically balanced and hydraulic effects in the radiator panel, i.e. hydraulic resistances, friction losses, are neglected.

- The conduction heat transfers through mounting and connecting parts are neglected.

- The air temperature in the room is equal to air temperature adjacent to radiator; thermal dynamics of heated air are not considered.

- The wall temperatures (include ceiling) are equal to initial room air temperature; the only exception is wall behind radiator's rear panel, which is one degree lower than room temperature.

- The specific heat capacity of steel is considered to be the radiator material's heat capacity; the heat capacities of coating and painting on the radiator surface are neglected.

\subsection{Control strategy}

PID controller is one of the most commonly used feedback controller. The control signal consists of three terms: P term which is proportional to the error, I term which is proportional to the integral of the error, and D term, which is proportional to the derivative of the error. It can be expressed by following equation:

$$
u(t)=K\left(e(t)+\frac{1}{T_{i}} \int_{0}^{t} e(\tau) d \tau+T_{d} \frac{d e(t)}{d t}\right)
$$

Where $\mathrm{K}$ is proportional gain, $\mathrm{T}_{\mathrm{i}}$ is integral time and $T_{d}$ is derivative time. In comparison with the prevailing proportional control strategy, PID controller provides more accurate and stable control. However, it also needs more complicated design, i.e. trial and tuning of parameters according to specific system requirement. Currently, only few manufacturers are providing PID controlled radiators, but this might become future market trend with more application and experience.

To apply the PID control strategy, a simplified room model was developed. The room volume is $40 \mathrm{~m}^{3}$ and with constant heat loss rates $(300 \mathrm{~W})$. The initial room temperature is same as outdoor temperature, $12^{\circ} \mathrm{C}$. Air in this room is regarded as perfectly mixed and there is no thermal stratification.

\section{Results}

The Matlab/Simulink models for both C22 and C33 radiator are built with afore-mentioned two different calculating approaches. The simulations ran $40 \quad 000$ seconds for each model. $55{ }^{\circ} \mathrm{C}$ water was supplied constantly by nominal flow rates. At the beginning of the simulations is the heating-up process for heat capacitances, then the heat output of the radiators reached stabilization. Fig. 4 presents the simulation results of ideal heat output curves for type $\mathrm{C} 22$ and $\mathrm{C} 33$ radiator, with the first 1400 seconds to illustrate the heating-up behavior. C33 takes more time to heat up the metal and water contained inside the radiator than $\mathrm{C} 22$, as it is heavier with both materials. It should be noted that the curves for both method show discontinuity at the beginning of simulation, but those for standard method are more noticeable in fig. 4 . Possible reason for this can be that the heat output is calculated according to outflow temperature, which is increasing slowly at the beginning due to the radiator materials heating-up process. In standard method it is an exponential function of outflow temperature while in heat transfer method it is mostly calculated in linear function, as shown in equation (3), (7) and (8). This implies that the standard method model can better describe the heating-up process. C22 reaches maximum heating power $919 \mathrm{~W}$ and $942 \mathrm{~W}$ with standard method and heat transfer method respectively; while type $\mathrm{C} 33$ delivers heating power $1269 \mathrm{~W}$ and $1226 \mathrm{~W}$ with two different methods. The deviations of heat output between two simulation strategies are $+2.61 \%$ for $\mathrm{C} 22$ and $-3.39 \%$ for C33. The model is then validated with different radiator length ranging from $700 \mathrm{~mm}$ to $1400 \mathrm{~mm}$ for both double panel and triple panel designs. Table 3 summarizes the deviations of heat output capacity between the two calculation approaches. In general, the deviations are assumed to be acceptable; for $\mathrm{C} 22$, the heat transfer model has higher heat output than standard method, while C33 is to the contrary.

Table 3. Deviations of heat output between standard and heat transfer method with different radiator lengths (mm)

\begin{tabular}{|c|c|c|c|c|c|c|c|}
\hline & $\mathbf{7 0 0}$ & $\mathbf{8 0 0}$ & $\mathbf{9 0 0}$ & $\mathbf{1 0 0 0}$ & $\mathbf{1 1 0 0}$ & $\mathbf{1 2 0 0}$ & $\mathbf{1 4 0 0}$ \\
\hline $\mathbf{C 2 2}$ & $4.20 \%$ & $3.81 \%$ & $3.63 \%$ & $2.61 \%$ & $2.08 \%$ & $2.36 \%$ & $1.24 \%$ \\
\hline $\mathbf{C 3 3}$ & $-1.58 \%$ & $-1.97 \%$ & $-2.28 \%$ & $-3.39 \%$ & $-4.01 \%$ & $-3.55 \%$ & $-4.68 \%$ \\
\hline
\end{tabular}



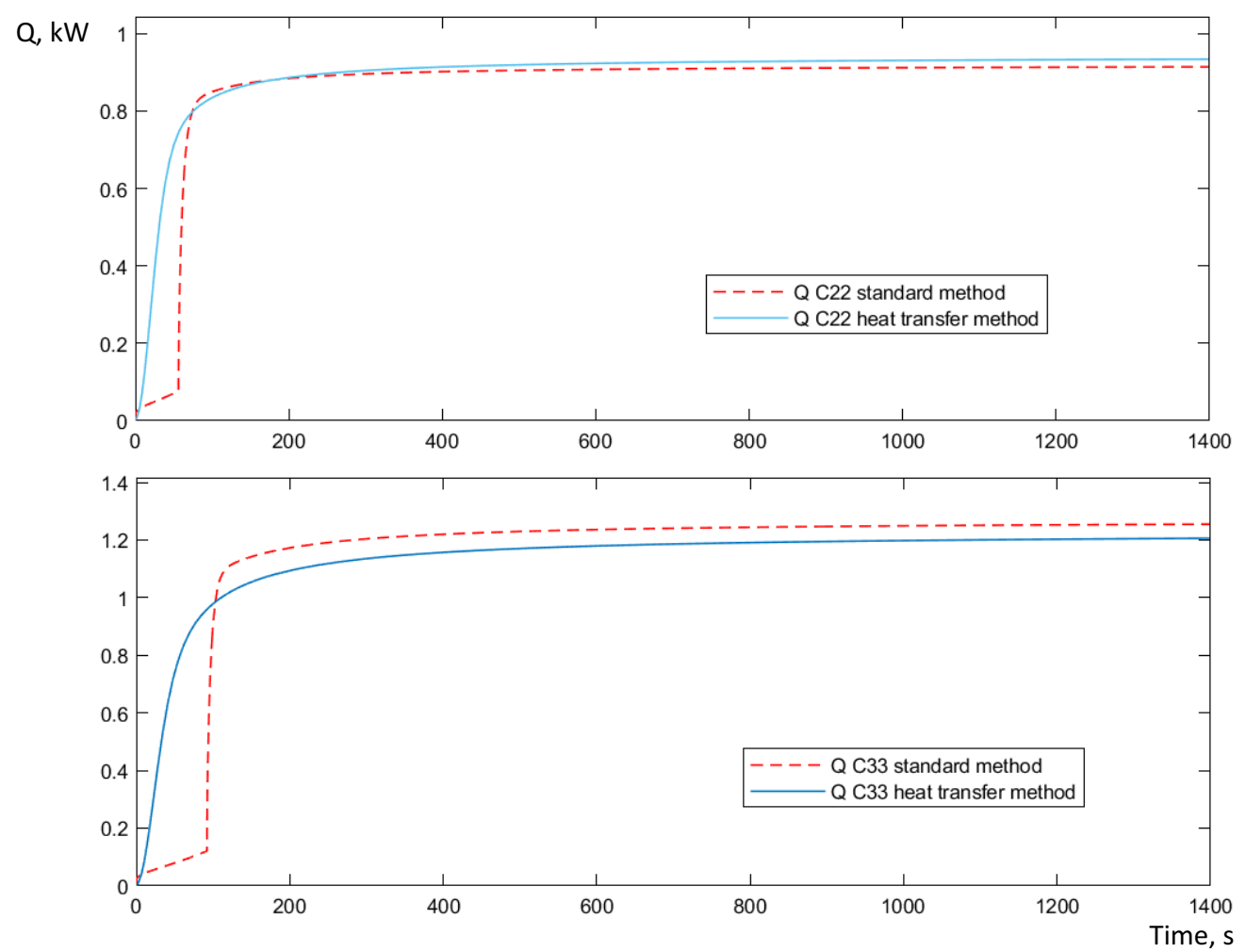

Fig. 4. Type $\mathrm{C} 22$ (top) and $\mathrm{C} 33$ (bottom) radiator ideal heating curves with two calculation methods

Table 4 summarizes convective and radiative heat transmitted from different radiator components in heat transfer model. The air temperature in the fin structure is assumed equal to mean temperature of initial air temperature and radiator surface. Radiation is calculated according to wall surface temperature and radiator surface temperature; the wall against rear panel is assumed with 1 ${ }^{\circ} \mathrm{C}$ lower temperature than the wall facing front panel. It should be noted that radiation takes up $27.2 \%$ and $22.1 \%$ of total heat emitted from $\mathrm{C} 22$ and $\mathrm{C} 33$ respectively. These numbers are lower than average data according to other researches $(27 \%-35 \%)[3,6]$, especially for C33. Reason for this is that in the heat transfer model, the increased radiator depth would notably raise the convective heat transfer through fins, but not radiation.

Table 4. Breakdown of heating power from different radiator components (500 mm*1000 $\mathrm{mm}$ for both types)

\begin{tabular}{|c|c|c|c|c|}
\hline & \multicolumn{2}{|c|}{ C22 } & \multicolumn{2}{c|}{ C33 } \\
\hline Radiation & 256 & $27.2 \%$ & 272 & $22.2 \%$ \\
\hline $\begin{array}{c}\text { Convection } \\
\text { fins }\end{array}$ & 500 & $53.1 \%$ & 759 & $61.9 \%$ \\
\hline $\begin{array}{c}\text { Convection } \\
\text { panels }\end{array}$ & 186 & $19.7 \%$ & 195 & $15.9 \%$ \\
\hline Sum & 942 & $100 \%$ & 1226 & $100 \%$ \\
\hline
\end{tabular}

As radiation through fin structure is neglected in the heat transfer model, with increased radiator depth, the heat output increases mostly due to convection rather than radiation.

For next step the radiator models are combined with a simple room model and controlled by PID controller. The controller parameters are chosen by trials; C22 and C33 adapt different sets of parameters. Supply water temperature is kept constant at $55^{\circ} \mathrm{C}$. Each simulation took 40000 seconds with the room temperature set point changed from $20{ }^{\circ} \mathrm{C}$ to $22{ }^{\circ} \mathrm{C}$ at 30000 seconds. Fig. 5 illustrates the heating power for each model. All the models response fast with changing room temperatures. It also indicates that, under the simulation scenario, C33 responses faster than $\mathrm{C} 22$, and it takes shorter time to reach steady heat output. Another noteworthy behavior is that when the room temperature changes from $12{ }^{\circ} \mathrm{C}$ to 20 ${ }^{\circ} \mathrm{C}$, C33 calculated with heat transfer method has the highest heat output rate; however, when the room temperature changes from $20^{\circ} \mathrm{C}$ to $22^{\circ} \mathrm{C}, \mathrm{C} 33$ calculated by standard method has the highest heat output rate. This implies that even with the same controlling parameters, the radiator's thermal performance can vary according to different operating environment. 


\section{$\mathrm{Q}, \mathrm{kW}$}

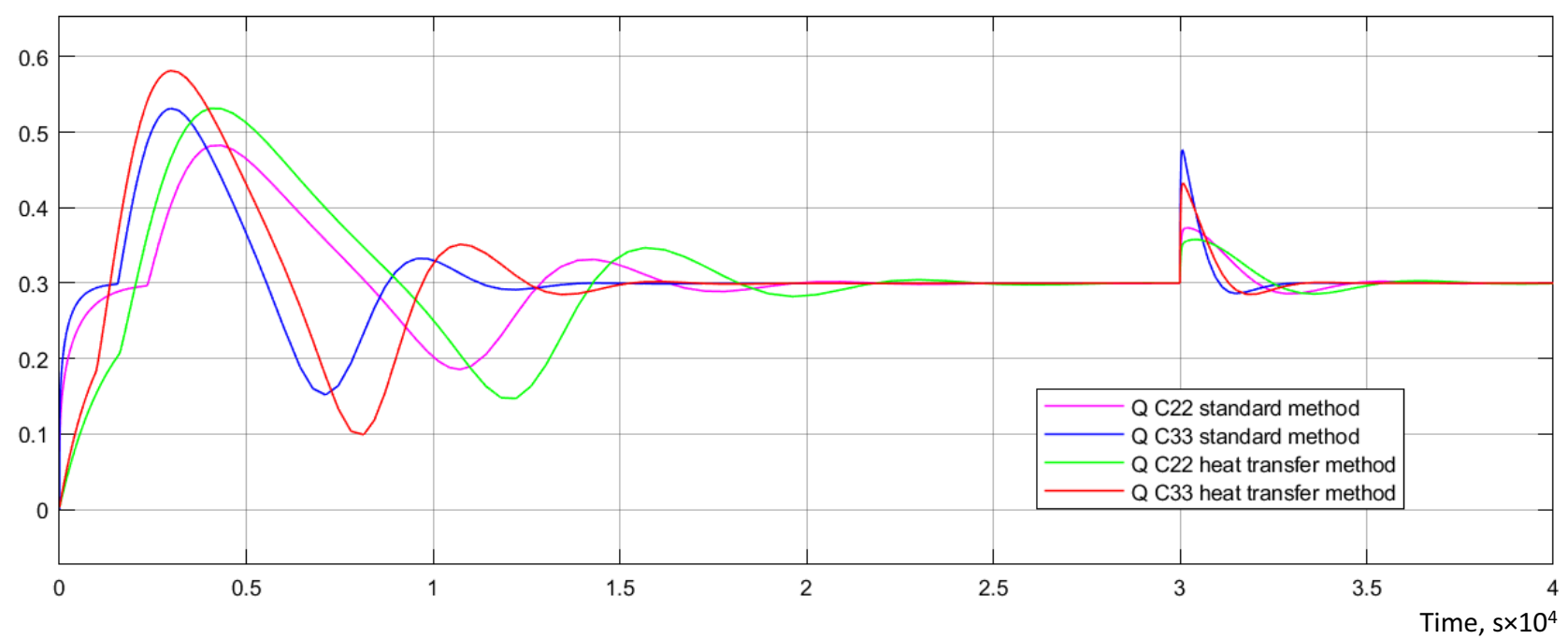

Fig. 5. Heat output with PID controller

Room temperature,

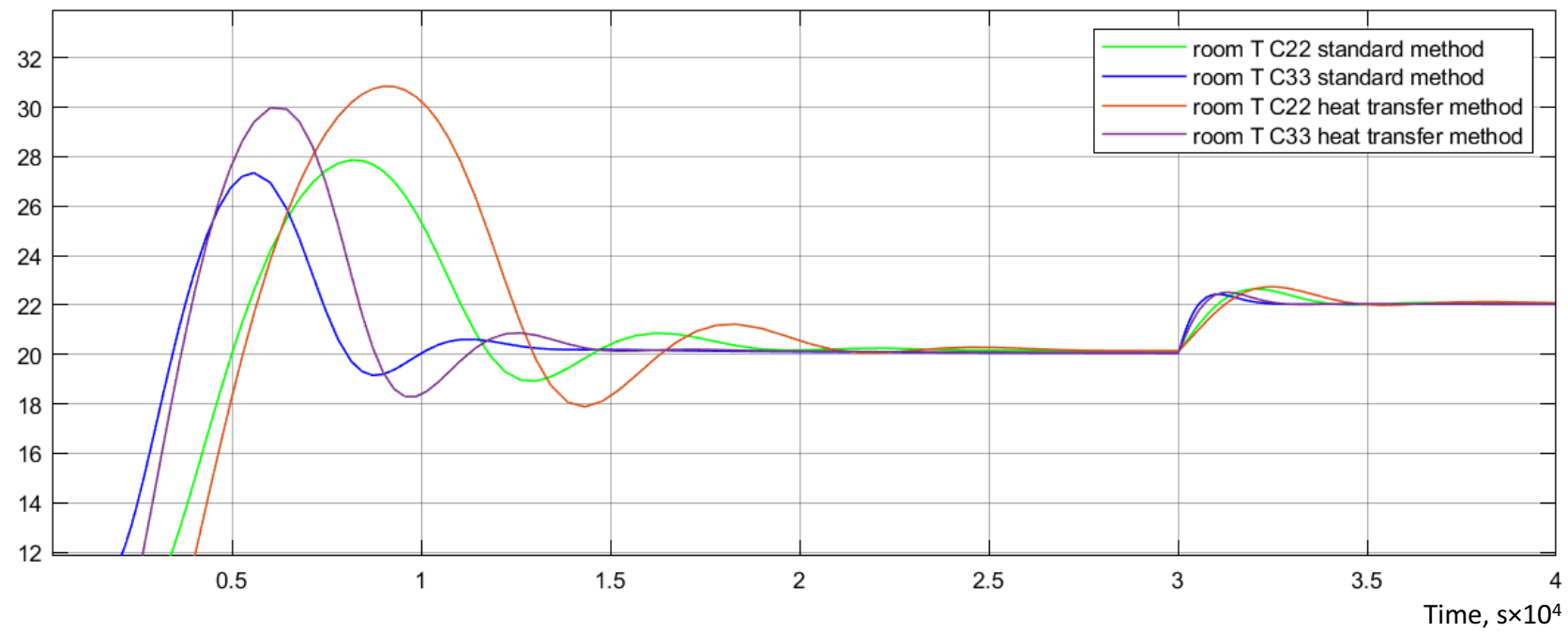

Fig. 6. Room temperature variations

Fluctuations of heat output rates lead to unstable room temperature, which are presented in Fig. 6. The room temperature increase from $12{ }^{\circ} \mathrm{C}$ and overshoot the set point for a while then stabilized after different period with each model. The four models show similar heating behaviors when the set point is changed from $20^{\circ} \mathrm{C}$ to 22 ${ }^{\circ} \mathrm{C}$. The highest over-heating temperature occurs with case C22 calculated with heat transfer method, which reaches $30.8{ }^{\circ} \mathrm{C}$ and $10.8{ }^{\circ} \mathrm{C}$ higher than set room temperature. Case C33 with standard method performs best considering overheating risk. In this case, the highest room temperature reaches $27.3^{\circ} \mathrm{C}$ when heating the room from $12{ }^{\circ} \mathrm{C}$ to $20^{\circ} \mathrm{C}$. The room temperature stabilized faster for models with heat transfer method. For example, when change the room temperature from 20 to $22^{\circ} \mathrm{C}$, case C33 with standard method takes 2500 seconds to stabilize (within $\pm 0.05{ }^{\circ} \mathrm{C}$ fluctuation); while with heat transfer method, the room temperature stabilization takes 2795 seconds.

Fig. 7 shows the variation of out flow water temperature. In general, C33 performs better than $\mathrm{C} 22$ as it has the lower out flow temperature with both simulation methods, which implies C33 utilizes energy more efficiently and requires lower water inflow rate. With standard calculation method, when room temperature is set at $20^{\circ} \mathrm{C}, \mathrm{C} 33$ has $22.3{ }^{\circ} \mathrm{C}$ out flow temperature, and this temperature is $24.6{ }^{\circ} \mathrm{C}$ when room temperature set point is $22{ }^{\circ} \mathrm{C}$. While for $\mathrm{C} 22$ with standard method, the out flow temperature is $24.8{ }^{\circ} \mathrm{C}$ and $27.3{ }^{\circ} \mathrm{C}$ with $20{ }^{\circ} \mathrm{C}$ and $22{ }^{\circ} \mathrm{C}$ room temperature respectively. The worst performance curve is $\mathrm{C} 22$ with heat transfer method, which has $31.5^{\circ} \mathrm{C}$ out flow temperature with $20^{\circ} \mathrm{C}$ room temperature and $33.5{ }^{\circ} \mathrm{C}$ out flow with $22{ }^{\circ} \mathrm{C}$ room temperature.

Fig. 5 and fig. 6 indicate that the controlling parameter can be optimized considering heating demands, as there are noticeable over- and undershoots when room temperature changes from $12{ }^{\circ} \mathrm{C}$ to $20^{\circ} \mathrm{C}$ for the first step. The response for second step is smoother, when room temperature changes from 20 to $22{ }^{\circ} \mathrm{C}$. Other method, for instance step response method can be applied for optimization of controlling strategy. 


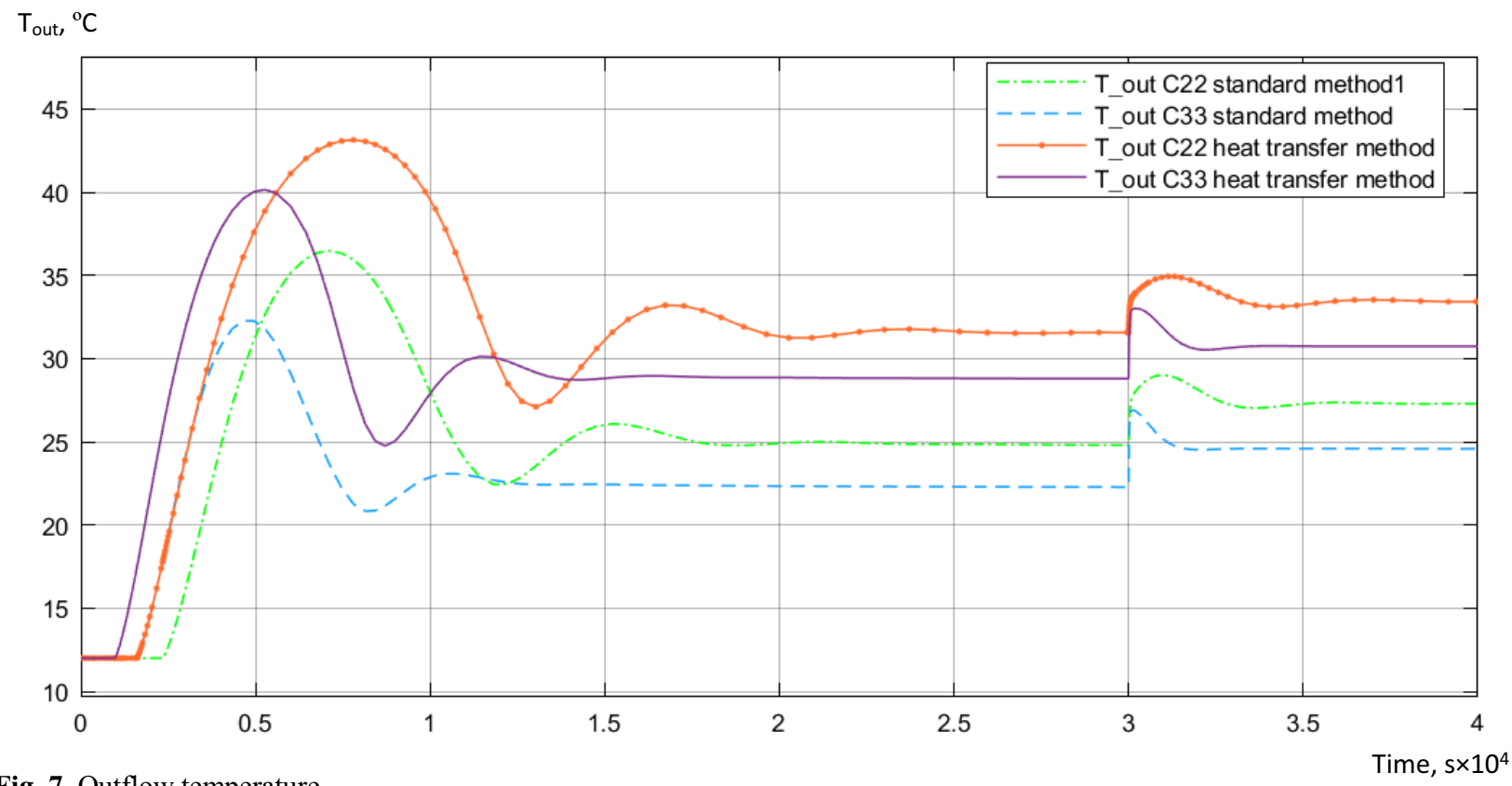

Fig. 7. Outflow temperature

\section{Conclusions}

This report provides some insights for hydronic radiators multi-layer designs through simulations by Matlab/Simulink. The models are based on two different approaches, namely calculation based on heat transfer theories and standard calculation with nominal heat output according to product specification provided by manufacturer. The simulation results indicate that, in comparison with $\mathrm{C} 22, \mathrm{C} 33$ respond faster with changing room temperature, and requires less time to reach stable condition. Moreover, the outflow temperature of $\mathrm{C} 33$ is lower than C22 in different simulation scenarios, which implies higher efficiency in heat emitting and energy utilization. However, increased radiator depth is not so efficient in improving thermal comfort.

It should be noted that there are noticeable deviations between heat transfer model and standard model. For future work, the radiator model can be improved regarding following aspects:

- Calculation for heat transfer parameters can be refined with more detailed investigations regarding radiator geometry and thermal dynamics of air.

- Consideration of fluid mechanics inside radiator's water channels.

- Other control strategies, i.e. thermostat and mixing valve, might be applied.

- Refined controlling parameter for PID controller. The radiators' thermal performances can vary greatly with different sets of controlling parameters.

- Integrating the radiator models with more comprehensive room model and climatic profile.

\section{Nomenclature}

$\mathrm{T}=$ Temperature

$\dot{Q}=$ Heating power

$\mathrm{c}=$ Specific heat capacity

$\mathrm{n}=$ Radiator exponent

$Q_{N}=$ Nominal heat output

$\mathrm{K}=$ Proportional gain

$\mathrm{T}_{\mathrm{i}}=$ Integral time

$T_{d}=$ Derivative time

$\mathrm{m}=$ Mass

$\mathrm{C}=$ Total heat capacitance

$\mathrm{h}=$ Convective heat transfer coefficient

$\varepsilon=$ Emissivity

$\sigma=$ Stefan-Boltzmann constant

$N u=$ Nusselt number

$k=$ Thermal conductivity

$R a=$ Rayleigh number

$\mathrm{Pr}=$ Prandtl number

$\beta=$ Thermal expansion coefficient

$v=$ Kinematic viscosity

$D_{h}=$ Hydraulic diameter $\left[{ }^{\circ} \mathrm{C}\right]$

[W]

$[\mathrm{J} / \mathrm{kg} \mathrm{K}]$

[-]

[W]

$[-]$

$[-]$

[-]

$[\mathrm{kg}]$

$[\mathrm{J} / \mathrm{K}]$

$\left[\mathrm{W} / \mathrm{m}^{2} \mathrm{~K}\right]$

[-] $\left[\mathrm{W} / \mathrm{m}^{2} \mathrm{~K}^{4}\right]$

[-]

[W/m K]

[-]

[-]

[-]

$\left[\mathrm{m}^{2} / \mathrm{s}\right]$

[m] 


\section{References}

1. M. Maivel, J.Kurniski, ENERG BUILDINGS, J. E 69(2014): p. 224-236.

2. M. Prek, G.Krese, Energy, J. E 161(2018): p. 52-59.

3. T. Pedersen, R. Hedegaard, K. Kristensen, B. Gadgaard, S. Petersen, ENERG BUILDINGS, J. E 183(2019): p. 772-784.

4. R. Karwa, Heat and mass transfer. 2017: Springer Nature.

5. F. Incropera, D. DeWitt, R. Bergman, A. Lavine, Fundamentals of heat and mass transfer. 6th. ed. 2007: John Wiley \& Sons.

6. C. Brembilla, M. Soleimani-Mohseni, T. Olofsson. 14th Conference of International Building Performance Simulation Association, 2015. 